\title{
Isolated genital psoriasis a new case report
}

\author{
Keywords: psoriasis, genital, squamous
}

\section{Introduction}

Psoriasis is a chronic inflammatory skin disease, affecting both sexs at any age. Genital skin can also be affected by the psoriasis and is relatively commun. ${ }^{1}$ The presentation of genital psoriasis (GP) may mimic other diseases and can be confused with sexually transmitted infections. ${ }^{2} \mathrm{GP}$ is often cause of discomfort and may even empair the patient's quality of life and specially sexual life. ${ }^{3}$ We report a case of genital lesions revealing a psoriasis. A 20 year-old man with no family history of psoriasis presented with itchy genital lesions evolving for the last two years on relapsing-remitting course. Clinical examination showed erythematosus and squamous plaques in the penile and scrotal skin, as well as a well demarcated erythema of the inguinal folds. Dermoscopy showed dotted vessels with a homogeneous distrubition. There was no phanerian or mucosal involvment. The patient was treated with potent topical steroids with a good outcome (Figure 1).

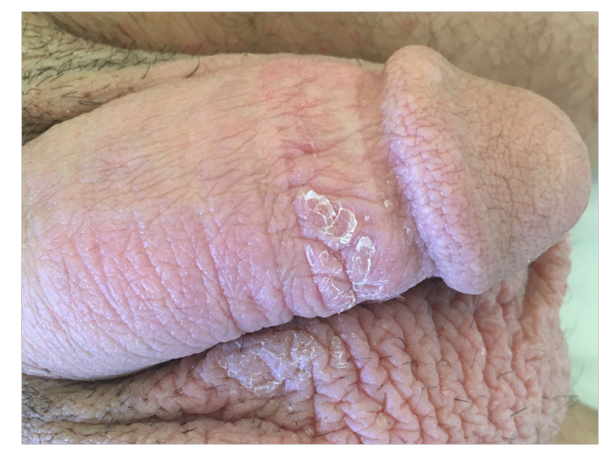

Figure I Erythematous and squamous plaque in the scotal and penile skin.
Volume 7 Issue 2 - 2019

\author{
S Ennaciri, 'S Mrabat, ${ }^{2}$ FZ Mernissi, ${ }^{2} \mathrm{MH}$ \\ Farih' \\ 'Departement of Urology, University Hospital Hassan II, \\ Morocco \\ ${ }^{2}$ Departement of Dermatology, University Hospital Hassan II, \\ Morocco
}

\author{
Correspondence: S Ennaciri, Department of Urology, \\ University Hospital Hassan II, Morocco, \\ Emailsoufenna@hotmail.com
}

Received: February 26, 2019 | Published: April 10, 2019

\section{Acknowledgments}

None.

\section{Conflicts of interest}

The authors declared there is no conflict of interest.

\section{References}

1. Cather JC, Ryan C, Meeuwis K, et al. Patients' perspectives on the impact of genital psoriasis: a qualitative study. Dermatol Ther (Heidelb). 2017;7(4):447-461.

2. Czuczwar P, Stępniak A, Goren A, et al. Genital psoriasis: a hidden multidisciplinary problem-a review of literature. Ginekol Pol. 2016;87(10):717-721.

3. Ryan C, Sadlier M, De Vol E, et al. Genital psoriasis is associated with significant impairment in quality of life and sexual functioning. $J \mathrm{Am}$ Acad Dermatol. 2015;72(6):978-83. 